\title{
3-PATHS IN GRAPHS WITH BOUNDED AVERAGE DEGREE
}

\author{
Stanislav Jendrol' ${ }^{1}$, Mária Maceková ${ }^{1}$ \\ MiCKaËl Montassier $^{2}$ AND ROMAN SOtÁK ${ }^{1}$ \\ ${ }^{1}$ Institute of Mathematics \\ P.J. Šafárik University in Košice \\ Jesenná 5, 04001 Košice, Slovakia \\ ${ }^{2}$ University Montpellier 2 \\ LIRMM, CNRS, UMR 5506, 161 Rue Ada \\ 34095 Montpellier Cedex 5, France \\ e-mail: stanislav.jendrol@upjs.sk \\ maria.macekova@student.upjs.sk \\ mickael.montassier@lirmm.fr \\ roman.sotak@upjs.sk
}

\begin{abstract} degree strictly less than $m$ contains a path of one of the types

- $(2, \infty, 2),(2,8,3),(4,3,5)$ if $m=\frac{15}{4}$,

- $(2, \infty, 2),(2,5,3),(3,2,4),(3,3,3)$ if $m=\frac{10}{3}$,

- $(2,2, \infty),(2,3,4),(2,5,2)$ if $m=3$,

- $(2,2,13),(2,3,3),(2,4,2)$ if $m=\frac{14}{5}$,

- $(2,2, i),(2,3,2)$ if $m=\frac{3(i+1)}{i+2}$ for $4 \leq i \leq 7$,

- $(2,2,3)$ if $m=\frac{12}{5}$, and

- $(2,2,2)$ if $m=\frac{9}{4}$.
\end{abstract}

In this paper we study the existence of unavoidable paths on three vertices in sparse graphs. A path $u v w$ on three vertices $u, v$, and $w$ is of type $(i, j, k)$ if the degree of $u$ (respectively $v, w$ ) is at most $i$ (respectively $j, k$ ). We prove that every graph with minimum degree at least 2 and average

Moreover, no parameter of this description can be improved.

Keywords: average degree, structural property, 3-path, degree sequence.

2010 Mathematics Subject Classification: 05C10. 
[1] K. Ando, S. Iwasaki and A. Kaneko, Every 3-connected planar graph has a connected subgraph with small degree sum, in: Annual Meeting of Mathematical Society of Japan, (1993), in Japanese.

[2] P. Bose, M. Smid and D.R. Wood, Light edges in degree-constrained graphs, Discrete Math. 28 (2004) 35-41.

doi:10.1016/j.disc.2003.12.003

[3] J.A. Bondy and U.S.R. Murty, Graph Theory (Springer, 2008).

[4] O.V. Borodin, A.O. Ivanova, T.R. Jensen, A.V. Kostochka and M. Yancey, Describing 3-paths in normal plane maps, Discrete Math. 313 (2013) 2702-2711. doi:10.1016/j.disc.2013.08.018

[5] O.V. Borodin, A.V. Kostochka, J. Nešetřil, A. Raspaud and E. Sopena, On the maximum average degree and the oriented chromatic number of a graph, Discrete Math. 206 (1999) 77-89.

doi:10.1016/S0012-365X(98)00393-8

[6] D.W. Cranston and D.B. West, A guide to the discharging method, arXiv: 1306.4434 [math.CO] 19 Jun 2013.

[7] S. Jendrol', A structural property of convex 3-polytopes, Geom. Dedicata 68 (1997) 91-99. doi:10.1023/A:1004993723280

[8] S. Jendrol' and M. Maceková, Describing short paths in plane graphs of girth at least 5, Discrete Math. 338 (2015) 149-158. doi:10.1016/j.disc.2014.09.014

[9] S. Jendrol', M. Maceková and R. Soták, Note on 3-paths in plane graphs of girth 4, Discrete Math. 338 (2015) 1643-1648.

doi:10.1016/j.disc.2015.04.011

Received 30 January 2015

Revised 7 July 2015

Accepted 7 July 2015 